\title{
E-cadherin involvement in human lens epithelial cell transdifferentiation may be associated with $\mathrm{N}$-cadherin
}

\author{
LEI HUANG, JIE JIANG, QIANG GUO and HONGBIN YANG \\ Department of Ophthalmology, The First Affiliated Hospital of Harbin Medical University, Nangang, \\ Harbin 150001, P.R. China
}

Received July 20, 2016; Accepted May 4, 2017

DOI: $10.3892 / \mathrm{mmr} .2017 .7132$

\begin{abstract}
E-cadherin, $\beta$-catenin and $\mathrm{N}$-cadherin serve key roles in the epithelial-to-mesenchymal transition (EMT) that leads to human lens epithelial cell (LEC) transdifferentiation and subsequent cataract formation. The present study aimed to investigate the role of E-cadherin in LEC transdifferentiation. SRA01/04 human LECs were transfected with E-cadherin short interfering (si)RNA (E-cadherin siRNA group), negative control siRNA (NC group) or the transfection regent Lipofectamine 2000 (blank group). Reverse transcription-quantitative polymerase chain reaction (RT-qPCR) was used to detect mRNA expression levels of E-cadherin, $\mathrm{N}$-cadherin and $\beta$-catenin, and western blot analysis was performed to measure the protein expression levels in the three groups. SRA01/04 cells transfected with E-cadherin siRNA exhibited a significant decrease in the mRNA expression level of $\mathrm{E}$-cadherin $(\mathrm{P}<0.05)$ and $\mathrm{N}$-cadherin $(\mathrm{P}<0.05)$, whereas no significant changes were identified for $\beta$-catenin expression $(\mathrm{P}>0.05)$. Consistent with the results of RT-qPCR, western blotting demonstrated that the protein expression levels of E-cadherin and $\mathrm{N}$-cadherin were notably decreased in E-cadherin siRNA-transfected cells, whereas the protein expression level of $\beta$-catenin remained unchanged. Results from the present study indicated that E-cadherin may be involved in human LEC transdifferentiation by affecting $\mathrm{N}$-cadherin expression.
\end{abstract}

\section{Introduction}

Cataracts affect $\sim 25$ million people worldwide and is the most common cause of blindness (1). Previous studies have reported that lens epithelial cells (LECs) may be induced by

Correspondence to: Professor Hongbin Yang, Department of Ophthalmology, The First Affiliated Hospital of Harbin Medical University, 23 Youzheng Street, Nangang, Harbin 150001, P.R. China E-mail: hongbinyang25@hotmail.com

Key words: E-cadherin, $\mathrm{N}$-cadherin, $\beta$-catenin, lens epithelial cells, epithelial-to-mesenchymal transdifferentiation transforming growth factor- $\beta$ (TGF- $\beta$ ) to undergo epithelial-to-mesenchymal transition (EMT), which may result in cataract formation $(2,3)$. EMT is characterized by the loss of epithelial marker expression (such as E-cadherin) and the gain in expression of mesenchymal markers (including vimentin and fibronectin) (4).

As a member of the classical cadherin family, epithelial (E)-cadherin is a calcium-dependent adhesion molecule that mediates cell-cell adhesion in a number of tissues in different species (5). The inhibition of E-cadherin and the suppression of glycogen synthase kinase-3 $\beta$ (GSK-3 $\beta$ ) activity mediated by integrin-linked kinase 1 (ILK-1) have previously been reported to be involved in EMT (6-8); E-cadherin may recruit $\beta$-catenin to form complexes that are also involved in EMT (9). As a member of an adhesion complex, $\beta$-catenin serves a pivotal role in linking the actin cytoskeleton with the cadherin-mediated cell-cell contacts in the cytoplasm (10), and the noncanonical $\beta$-catenin signaling pathway has been considered crucial for mediating EMT (11). In addition, it has been demonstrated that decreased E-cadherin expression may lead to the release of $\beta$-catenin into the cytoplasm, which may migrate into the nucleus and activate the expression of certain transcription factors that induce EMT (12). Neural (N)-cadherin also belongs to the classical cadherin superfamily and mediates calcium-dependent cell-cell adhesion (13); N-cadherin has been referred as a mesenchymal cadherin that is associated with EMT (14). A previous study demonstrated that $\mathrm{N}$-cadherin protein expression and $\beta$-catenin nuclear translocation may be repressed by injury of cultured retinal pigment epithelial cells treated with peroxide (15). Another report revealed that the gain of $\mathrm{N}$-cadherin expression and the loss of E-cadherin expression (known as 'cadherin switching') is a major hallmark of EMT (16). However, it is unknown whether there is a transcriptional regulatory relationship between E-cadherin, $\beta$-catenin and $\mathrm{N}$-cadherin.

In the present study, E-cadherin short interfering RNA (siRNA) transfection was used to knock down the expression of E-cadherin in the SRA01/04 human lens epithelial cell (LEC) line. Subsequently, reverse transcription-quantitative polymerase chain reaction (RT-qPCR) and western blot analyses were used to investigate the effects on mRNA and protein expression levels, respectively, of E-cadherin, N-cadherin and $\beta$-catenin to examine the role of E-cadherin in EMT of human LECs. 


\section{Materials and methods}

Culture of human LEC line SRA01/04. The SRA01/04 human LEC line was purchased from Shanghai SXBIO Biotechnology Co., Ltd. (Shanghai, China). SRA01/04 cells were cultured in the Dulbecco's modified Eagle's medium/Ham's F12 (DMEM/F12; 1:1) supplemented with $10 \%$ fetal bovine serum (FBS) and 1\% penicillin-streptomycin (all from Gibco; Thermo Fisher Scientific, Inc., Waltham, MA, USA) in a humidified $5 \% \mathrm{CO}_{2}$ incubator at $37^{\circ} \mathrm{C}$. SRA01/04 cells were grown to $80-90 \%$ confluence, digested with a $0.25 \%$ trypsin-0.02\% ethylenediamine-N,N,N',N'-tetraacetic acid solution (Gibco; Thermo Fisher Scientific, Inc.), centrifuged at $100 \mathrm{x} \mathrm{g}$ for $5 \mathrm{~min}$ at room temperature and transferred into a new culture dish for passage. SRA01/04 cells were stored in frozen stock solution at $-80^{\circ} \mathrm{C}$ containing $10 \%$ dimethyl sulfoxide (Sigma-Aldrich; Merck KGaA, Darmstadt, Germany), $40 \% \mathrm{FBS}$ and $50 \%$ DMEM/F12.

E-cadherin siRNA transfection. Human E-cadherin siRNA and negative control (NC) siRNA was purchased from Shanghai GenePharmaCo.,Ltd.(Shanghai,China). The siRNA sequences were as follows: E-cadherin siRNA forward, 5'-GAGGCUGUA UACACCAUAUTT-3' and reverse, 5'-AUAUGGUGUAUA CAGCCUCTT-3'; NC siRNA forward, 5'-UUCUCCGAACGU GUCACGUTT-3' and reverse, 5'-ACGUGACACGUUCGG AGAATT-3'. SRA01/04 cells $\left(3 \times 10^{5}\right)$ were seeded into a 6-well plate with $2 \mathrm{ml}$ antibiotic-free DMEM/F12 medium $24 \mathrm{~h}$ prior to transfection at $37^{\circ} \mathrm{C}$. Healthy, well-adhered $70-90 \%$ confluent cells were used for transfection. E-cadherin and $\mathrm{NC}$ siRNAs were diluted in $250 \mu \mathrm{l}$ Opti-MEM medium (Gibco; Thermo Fisher Scientific, Inc.) to make a concentration of $20 \mu \mathrm{M}$ stock solution; $3.3 \mu \mathrm{l}$ stock solution was subsequently added to a 6-well plate to a final concentration of $66 \mathrm{nM}$ and mixed gently 3-5 times. Lipofectamine 2000 transfection reagent (10 $\mu \mathrm{l}$; Invitrogen; Thermo Fisher Scientific, Inc.) was diluted in $250 \mu$ l Opti-MEM, mixed and incubated for $5 \mathrm{~min}$ at room temperature. The diluted siRNA and transfection reagent were combined and incubated at room temperature for $20 \mathrm{~min}$. Subsequently, $500 \mu 1$ of the mixture was added to each well of the 6-well plate and mixed. Cells were transfected with the E-cadherin siRNA (siRNA group), the NC siRNA (NC group) or with Lipofectamine 2000 (blank group) and were cultured at $37^{\circ} \mathrm{C}$ in a $5 \% \mathrm{CO}_{2}$ incubator for $48 \mathrm{~h}$; the medium was replaced with fresh antibiotic-free medium following $12 \mathrm{~h}$ of transfection.

Total RNA isolation and RT-qPCR analysis. Total RNA was extracted from $1 \times 10^{6}$ cultivated cells using the RNAiso Plus kit (Takara Bio, Inc., Otsu, Japan) according to the manufacturer's protocol. Briefly, cells were lysed in $1 \mathrm{ml}$ RNAiso Plus for $5 \mathrm{~min}$ at room temperature. The lysate was centrifuged at $12,000 \mathrm{x} \mathrm{g}$ for $5 \mathrm{~min}$ at $4^{\circ} \mathrm{C}$, and the aqueous phase containing RNA was separated from the organic phase via incubation with $200 \mu \mathrm{l}$ chloroform for $5 \mathrm{~min}$ at room temperature. The solution was subsequently centrifuged at 12,000 x g for $15 \mathrm{~min}$ at $4^{\circ} \mathrm{C}$, and the supernatant was transferred into a new tube and incubated with $700 \mu \mathrm{l}$ isopropanol for $10 \mathrm{~min}$ at room temperature. RNA was precipitated via centrifugation at 12,000 $\mathrm{x}$ g for $10 \mathrm{~min}$ at $4^{\circ} \mathrm{C}$. The RNA pellet was washed with $75 \%$ ethanol,
Table I. Sequences of primers used for reverse transcription-quantitative polymerase chain reaction.

\begin{tabular}{ll}
\hline Gene & \multicolumn{1}{c}{ Primer sequence $\left(5^{\prime} \rightarrow 3^{\prime}\right)$} \\
\hline E-cadherin & F: GAGAACGCATTGCCACATACA \\
& R: ACCTTCCATGACAGACCCCTTAA \\
N-cadherin & F: TCTCTCACGCTGTGTCATCCAAC \\
& R: CACAGAGGTTCCTGGAAGAGCAC \\
$\beta$-catenin & F: CAATGACTCGAGCTCAGAGGGTAC \\
& R: TTTAGCAGTTTTTCAGTTCAGGGA \\
GAPDH & F: AATCCCATCACCATCTTCCAG \\
& R: ATCAGCAGAGGGGGCAGAGA
\end{tabular}

E, epithelial; N, neural; F, forward; R, reverse.

air dried for 5-10 min and redissolved in 30 $\mu$ l diethyl pyrocarbonate (DEPC)-treated water. To assess the quality of RNA, A260/A280 and A260/A230 ratios of the RNA samples were measured using an SMA4000 Ultraviolet spectrophotometer (Merinton Instruments, Ltd., Beijing, China). An A260/A280 ratio between 2.0 and 2.3 was considered high quality RNA (17) and was used for the subsequent experiments.

cDNA was synthesized using a PrimeScript RT-PCR kit (Takara Bio, Inc.) according to the manufacturer's protocol. Primers for E-cadherin, N-cadherin, $\beta$-catenin and glyceraldehyde-3-phosphate dehydrogenase (GAPDH) were obtained from Shanghai Sangon Biological Engineering Technology \& Services Co., Ltd. (Shanghai, China; Table I). qPCR reactions were set up as follows: $10 \mu 1$ SYBR Premix Ex Taq (2X; Takara Bio, Inc.), $1 \mu \mathrm{l}$ forward primer $(10 \mu \mathrm{M}), 1 \mu \mathrm{l}$ reverse primer $(10 \mu \mathrm{M}), 2 \mu \mathrm{l}$ cDNA (adjusted to the same concentration) and $6 \mu \mathrm{l}$ double-distilled $\mathrm{H}_{2} \mathrm{O}$. qPCR was performed using a ViiA 7 Real-Time PCR system (Applied Biosystems; Thermo Fisher Scientific, Inc.) with the following conditions: $50.0^{\circ} \mathrm{C}$ for $3 \mathrm{~min}$ and $95.0^{\circ} \mathrm{C}$ for $3 \mathrm{~min}$; followed by 40 cycles of $95.0^{\circ} \mathrm{C}$ for $10 \mathrm{sec}$ and $60.0^{\circ} \mathrm{C}$ for $30 \mathrm{sec}$; followed by melting curve construction and analysis. GAPDH was used as a reference gene. Each sample was repeated three times, and calculation of gene expression was performed by the $2^{-\Delta \Delta \mathrm{Cq}}$ method (18).

Protein extraction and western blot analysis. A total of $5 \times 10^{6}$ SRA01/04 cells were washed three times with pre-cooled phosphate-buffered saline (Gibco, Thermo Fisher Scientific, Inc.) and lysed at $4^{\circ} \mathrm{C}$ for $30 \mathrm{~min}$ with radioimmunoprecipitation assay lysis buffer (Beyotime Institute of Biotechnology, Shanghai, China) containing $1 \%$ phenylmethylsulfonyl fluoride (Sigma-Aldrich; Merck KGaA). The supernatant without cell debris was obtained by centrifugation at $19,000 \mathrm{x} \mathrm{g}$ for $10 \mathrm{~min}$ at $4^{\circ} \mathrm{C}$. Protein concentration was determined by Bicinchoninic Acid Protein Assay kit (Sangon Biotech, Co., Ltd., Shanghai, China) according to the manufacturer's instruments.

A total of $30 \mu \mathrm{g}$ protein was loaded in each well and separated by $10 \%$ (w/v) SDS-PAGE (Bio-Rad Laboratories, Inc., Hercules, CA, USA). Proteins were transferred onto a polyvinylidene fluoride membrane (Merck KGaA) and blocked with $5 \%$ non-fat dry milk for $1 \mathrm{~h}$ at room temperature. The 

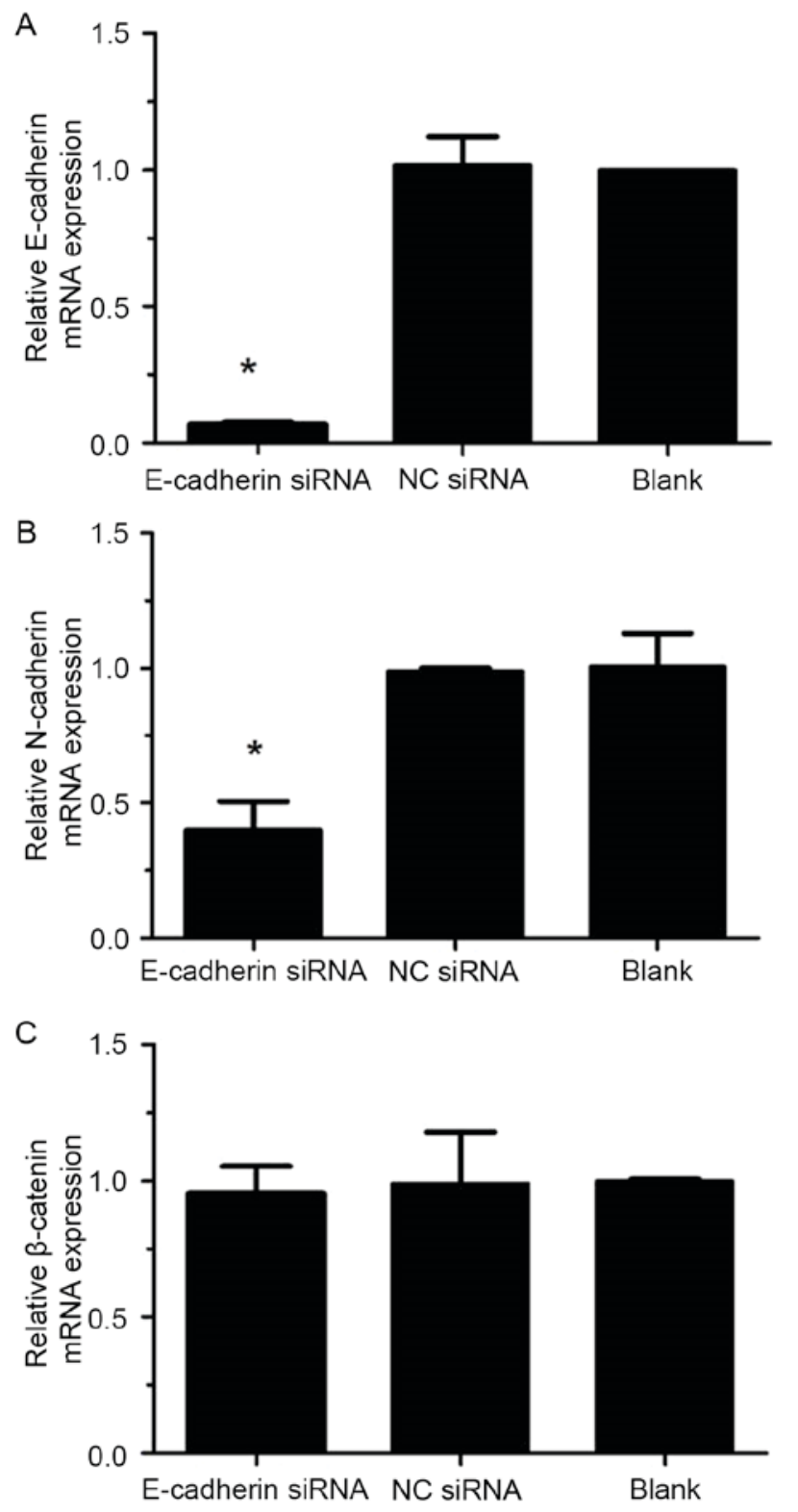

Figure 1. Reverse transcription-quantitative polymerase chain reaction analysis for E-cadherin, $\mathrm{N}$-cadherin and $\beta$-catenin expression. The expression levels of (A) E-cadherin, (B) N-cadherin and (C) $\beta$-catenin in SRA01/04 human lens epithelial cells transfected with E-cadherin siRNA, NC siRNA or neither (Blank). Results are presented as the mean \pm standard error of the mean from three independent experiments; ${ }^{*} \mathrm{P}<0.05$ vs. NC siRNA group. $\mathrm{E}$, epithelial; N, neural; NC, negative control; siRNA, short interfering RNA.

membrane was probed overnight at $4^{\circ} \mathrm{C}$ with the following primary antibodies: rabbit anti-GAPDH (1:5,000; BM1623; Wuhan Boster Biological Technology, Ltd., Wuhan, China), rabbit anti-E-cadherin (1:500; 20874-1-AP; Wuhan Sanying Biotechnology, Wuhan, China), rabbit anti-N-cadherin (1:100; BA0673) and rabbit anti- $\beta$-catenin (1:100; BM3905) (both from Wuhan Boster Biological Technology, Ltd.). Following 3 washes with TBS $+0.05 \%$ Tween-20 (TBST), the membranes were incubated with the secondary horseradish peroxidase-conjugated goat-anti-rabbit immunoglobulin $\mathrm{G}$ antibody (1:5,000; 111-035-045; Jackson ImmunoResearch Laboratories, Inc., West Grove, PA, USA) for $1 \mathrm{~h}$. Membranes were washed with 1X TBST buffer, and the formed immunocomplexes

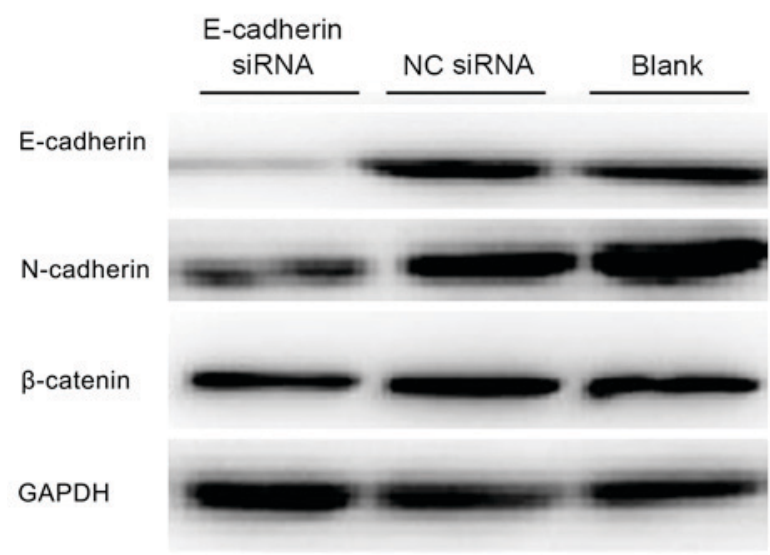

Figure 2. Western blot analysis for E-cadherin, $\mathrm{N}$-cadherin and $\beta$-catenin protein expression. SRA01/04 human lens epithelial cells were transfected with E-cadherin siRNA, NC siRNA or neither (blank), and the protein expression of E-cadherin, $\mathrm{N}$-cadherin and $\beta$-catenin were analyzed by western blotting. E, epithelial; N, neural; NC, negative control; siRNA, short interfering RNA.

were visualized by Enhanced Chemiluminescence reagent (Merck KGaA). Densitometric analysis was performed with Quantity One software (version 4.5.2) on the ChemiDoc XRS Gel Imaging system (both from Bio-Rad Laboratories, Inc., Hercules, CA, USA). Western blot analysis was repeated three times.

Statistical analysis. Statistical analysis was conducted using SPSS software version 11.0 (SPSS, Chicago, IL, USA). The data are presented as the mean \pm standard error of the mean. One-way analysis of variance (19) and the post-hoc Duncan's multiple range tests (20) were used to determine statistical significance. $\mathrm{P}<0.05$ was considered to indicate a statistically significant difference.

\section{Results}

Gene expression levels of E-cadherin, $N$-cadherin and $\beta$-catenin. The mRNA expression levels of E-cadherin, $\mathrm{N}$-cadherin and $\beta$-catenin in the E-cadherin siRNA, NC siRNA and Blank groups were detected by RT-qPCR (Fig. 1). Following $48 \mathrm{~h}$ E-cadherin siRNA transfection, the expression level of E-cadherin was significantly downregulated in the E-cadherin siRNA group compared with those in the NC siRNA and Blank groups $(\mathrm{P}<0.05$; Fig. 1A). The mRNA expression level of $\mathrm{N}$-cadherin in the E-cadherin siRNA group was also significantly reduced $(\mathrm{P}<0.05$; Fig. $1 \mathrm{~B})$. However, the expression level of $\beta$-catenin was unaltered compared with those in the NC siRNA and Blank groups ( $\mathrm{P}>0.05$; Fig. 1C).

Protein expression of $E$-cadherin, $N$-cadherin and $\beta$-catenin . To investigate the protein levels of the E-cadherin, $\mathrm{N}$-cadherin and $\beta$-catenin, western blotting was conducted (Fig. 2). Consistent with the RT-qPCR results aforementioned, the protein expression levels of E-cadherin and $\mathrm{N}$-cadherin were reduced in the E-cadherin siRNA group compared with the NC siRNA and Blank groups, and the protein expression level of $\beta$-catenin had no notable changes. 


\section{Discussion}

Cadherins are a group of calcium-dependent cell adhesion molecules that function through homophilic interactions to maintain cell-cell adhesion (21). The classical cadherins, which include E- and N-cadherin, as well as placental- and retinal-cadherin) are single-pass transmembrane glycoproteins that have a large degree of structural similarity and regulate cell-cell contacts through their extracellular amino terminus (22). E-cadherin and $\mathrm{N}$-cadherin have been revealed to be pivotal mediators of cell adhesion that maintain cell-cell contacts (23). Immunofluorescence and in situ hybridization analyses demonstrated that E-cadherin, $\mathrm{N}$-cadherin and P-cadherin have distinct expression patterns in the lens during development $(24,25)$. A previous study revealed that the cooperative expression of $\mathrm{N}$-cadherin and E-cadherin serve an important role in normal cell sorting and subsequent separation of the invaginated lens vesicle from the surface ectoderm (23). In the present study, E-cadherin expression was inhibited by transfecting human LECs with E-cadherin siRNA. RT-qPCR and western blot analysis revealed that the expression of E-cadherin was significantly downregulated following transfection with E-cadherin siRNA, which indicated that E-cadherin was successfully silenced. In addition, the expression of $\mathrm{N}$-cadherin was also significantly decreased in E-cadherin siRNA transfected LECs.

A previous study reported that the decreased expression of E-cadherin and the induction of $\mathrm{N}$-cadherin expression was a mediator of EMT (26). TGF- $\beta$ was demonstrated to enhance tumor progression by promoting EMT, and TGF- $\beta$-induced EMT are characterized by a loss of junctional E-cadherin localization, overexpression of $\mathrm{N}$-cadherin, the acquisition of a fibroblastoid morphology and increased cellular motility (27). Furthermore, the expression of $\mathrm{N}$-cadherin was reported to lead to a mesenchymal phenotype (28), and the overexpression of N-cadherin, which is influenced by growth factors, has been implicated in EMT (29). Therefore, the present study hypothesized that LECs may be able to shut off EMT by downregulating the expression of $\mathrm{N}$-cadherin, which may lead to a decrease in the occurrence of cataracts.

In addition, RT-qPCR and western blot analysis demonstrated that the mRNA and protein expression levels of $\beta$-catenin were unaffected in LECs transfected with E-cadherin siRNA. Previous studies have reported that cadherins are able to link the extracellular environment to the actin cytoskeleton through interactions with intracellular $\beta$-catenin $(21,30)$. Therefore, the present study hypothesized that following E-cadherin siRNA exposure, LECs would not be able to form the $\beta$-catenin/E-cadherin complex, thus decreasing the adhesion among cells and resulting in EMT. Previous studies have demonstrated that $\beta$-catenin functions in lens fiber differentiation and is associated with both Wnt signaling and adhesion-related mechanisms that mediate early fiber and lens epithelium differentiation $(31,32)$. Activation of the $\beta$-catenin/T cell factor (TCF) pathway and inhibition of E-cadherin were reported to be induced by upregulated gene 11, which regulates hypoxia-induced EMT (33). The loss of E-cadherin may give rise to increased $\beta$-catenin/TCF signaling, which cooperates with autocrine TGF- $\beta$ signaling to sustain an undifferentiated mesenchymal phenotype (34).
However, in the present study, the expression of E-cadherin siRNA had no influence on the expression of $\beta$-catenin, which may be caused an insufficient transfection time of E-cadherin siRNA.

In conclusion, the present study investigated the potential action mechanism of E-cadherin in the regulation of human LEC transdifferentiation, which may occur via the regulation of $\mathrm{N}$-cadherin levels. Further study is necessary to investigate the association between $\beta$-catenin with E-cadherin.

\section{References}

1. Chang MA, Congdon NG, Baker SK, Bloem MW, Savage H and Sommer A: The surgical management of cataract: Barriers, best practices and outcomes. Int Ophthalmol 28: 247-260, 2008.

2. Lovicu FJ and McAvoy JW: Growth factor regulation of lens development. Dev Biol 280: 1-14, 2005.

3. Lovicu FJ, Ang S, Chorazyczewska M and McAvoy JW: Deregulation of lens epithelial cell proliferation and differentiation during the development of TGFbeta-induced anterior subcapsular cataract. Dev Neurosci 26: 446-455, 2004.

4. Theys J, Jutten B, Habets R, Paesmans K, Groot AJ, Lambin P, Wouters BG, Lammering $\mathrm{G}$ and Vooijs M: E-Cadherin loss associated with EMT promotes radioresistance in human tumor cells. Radiother Oncol 99: 392-397, 2011.

5. Van Roy F and Berx G: The cell-cell adhesion molecule E-cadherin. Cell Mol Life Sci 65: 3756-3788, 2008.

6. Somasiri A, Howarth A, Goswami D, Dedhar S and Roskelley CD: Overexpression of the integrin-linked kinase mesenchymally transforms mammary epithelial cells. J Cell Sci 114: 1125-1136, 2001.

7. Teixeira Vde P, Blattner SM, Li M, Anders HJ, Cohen CD, Edenhofer I, Calvaresi N, Merkle M, Rastaldi MP and Kretzler M: Functional consequences of integrin-linked kinase activation in podocyte damage. Kidney Int 67: 514-523, 2005.

8. Tan C, Costello P, Sanghera J, Dominguez D, Baulida J, de Herreros AG and Dedhar S: Inhibition of integrin linked kinase (ILK) suppresses beta-catenin-Lef/Tcf-dependent transcription and expression of the E-cadherin repressor, snail, in APC-/-human colon carcinoma cells. Oncogene 20: 133-140, 2001.

9. Tian X, Liu Z, Niu B, Zhang J, Tan TK, Lee SR, Zhao Y, Harris DC and Zheng G: E-cadherin/ $\beta$-catenin complex and the epithelial barrier. J Biomed Biotechnol 2011: 567305, 2011.

10. Shtutman M, Zhurinsky J, Simcha I, Albanese C, D'amico M, Pestell R and Ben-Ze'ev A: The cyclin D1 gene is a target of the beta-catenin/LEF-1 pathway. Proc Natl Acad Sci USA 96: 5522-5527, 1999.

11. Douglas IS, Diaz del Valle F, Winn RA and Voelkel NF: Beta-catenin in the fibroproliferative response to acute lung injury. Am J Respir Cell Mol Biol 34: 274-285, 2006.

12. Polyak K and Weinberg RA: Transitions between epithelial and mesenchymal states: Acquisition of malignant and stem cell traits. Nat Rev Cancer 9: 265-273, 2009.

13. Vunnam N and Pedigo S: Calcium-induced strain in the monomer promotes dimerization in neural cadherin. Biochemistry 50: 8437-8444, 2011.

14. Zhang X, Liu G, Kang Y, Dong Z, Qian Q and Ma X: N-cadherin expression is associated with acquisition of EMT phenotype and with enhanced invasion in erlotinib-resistant lung cancer cell lines. PLoS One 8: e57692, 2013.

15. Bailey TA, Kanuga N, Romero IA, Greenwood J, Luthert PJ and Cheetham ME: Oxidative stress affects the junctional integrity of retinal pigment epithelial cells. Invest Ophthalmol Vis Sci 45: 675-684, 2004.

16. Nguyen PT, Kudo Y, Yoshida M, Kamata N, Ogawa I and Takata T: $\mathrm{N}$-cadherin expression is involved in malignant behavior of head and neck cancer in relation to epithelial-mesenchymal transition. Histol Histopathol 26: 147-156, 2011.

17. Skrypina NA, Timofeeva AV, Khaspekov GL, Savochkina LP and Beabealashvilli RSh: Total RNA suitable for molecular biology analysis. J Biotechnol 105: 1-9, 2003.

18. Livak KJ and Schmittgen TD: Analysis of relative gene expression data using real-time quantitative PCR and the 2(-Delta Delta C(T)) method. Methods 25: 402-408, 2001.

19. Heiberger RM and Neuwirth E: One-way Anova. In: R through Excel. Springer, pp165-191, 2009. 
20. Tallarida RJ and Murray RB: Duncan multiple range test. In: Manual of Pharmacologic Calculations. Springer, pp125-127, 1987.

21. Perez-Moreno M, Jamora C and Fuchs E: Sticky business: Orchestrating cellular signals at adherens junctions. Cell 112: 535-548, 2003.

22. Goodwin M and Yap AS: Classical cadherin adhesion molecules: Coordinating cell adhesion, signaling and the cytoskeleton. J Mol Histol 35: 839-844, 2004

23. Pontoriero GF, Smith AN, Miller LA, Radice GL, West-Mays JA and Lang RA: Co-operative roles for E-cadherin and N-cadherin during lens vesicle separation and lens epithelial cell survival. Dev Biol 326: 403-417, 2009.

24. Pontoriero GF, Deschamps P, Ashery-Padan R, Wong R, Yang Y, Zavadil J, Cvekl A, Sullivan S, Williams T and West-Mays JA: Cell autonomous roles for AP-2alpha in lens vesicle separation and maintenance of the lens epithelial cell phenotype. Dev Dyn 237: 602-617, 2008.

25. Xu L, Overbeek PA and Reneker LW: Systematic analysis of E-, $\mathrm{N}$ - and P-cadherin expression in mouse eye development. Exp Eye Res 74: 753-760, 2002.

26. Araki K, Shimura T, Suzuki H, Tsutsumi S, Wada W, Yajima T, Kobayahi T, Kubo $\mathrm{N}$ and Kuwano H: E/N-cadherin switch mediates cancer progression via TGF- $\beta$-induced epithelial-to-mesenchymal transition in extrahepatic cholangiocarcinoma. Br J Cancer 105: 1885-1893, 2011.

27. Bhowmick NA, Ghiassi M, Bakin A, Aakre M, Lundquist CA, Engel ME, Arteaga CL and Moses HL: Transforming growth factor-beta1 mediates epithelial to mesenchymal transdifferentiation through a RhoA-dependent mechanism. Mol Biol Cell 12 27-36, 2001.
28. Rosivatz E, Becker I, Specht K, Fricke E, Luber B, Busch R, Höfler $\mathrm{H}$ and Becker KF: Differential expression of the epithelial-mesenchymal transition regulators snail, SIP1, and twist in gastric cancer. Am J Pathol 161: 1881-1891, 2002.

29. Nakajima S, Doi R, Toyoda E, Tsuji S, Wada M, Koizumi M, Tulachan SS, Ito D, Kami K, Mori T, et al: N-cadherin expression and epithelial-mesenchymal transition in pancreatic carcinoma. Clin Cancer Res 10: 4125-4133, 2004.

30. Perez-Moreno M and Fuchs E: Catenins: Keeping cells from getting their signals crossed. Dev Cell 11: 601-612, 2006.

31. Cain S, Martinez G, Kokkinos MI, Turner K, Richardson RJ, Abud HE, Huelsken J, Robinson ML and De Iongh RU: Differential requirement for beta-catenin in epithelial and fiber cells during lens development. Dev Biol 321: 420-433, 2008.

32. Antosova B, Smolikova J, Borkovcova R, Strnad H, Lachova J, Machon O and Kozmik Z: Ectopic activation of Wnt/ $\beta$-catenin signaling in lens fiber cells results in cataract formation and aberrant fiber cell differentiation. PLoS One 8: e78279, 2013.

33. Du R, Huang C, Bi Q, Zhai Y, Xia L, Liu J, Sun S and Fan D: URG11 mediates hypoxia-induced epithelial-to-mesenchymal transition by modulation of E-cadherin and beta-catenin. Biochem Biophys Res Commun 391: 135-141, 2010.

34. Eger A, Stockinger A, Park J, Langkopf E, Mikula M, Gotzmann J, Mikulits W, Beug H and Foisner R: beta-Catenin and TGFbeta signalling cooperate to maintain a mesenchymal phenotype after FosER-induced epithelial to mesenchymal transition. Oncogene 23: 2672-2680, 2004. 